\title{
Thermography-Based Virtual MPPT Scheme for Improving PV Energy Efficiency under Partial Shading Conditions
}

\author{
Yihua Hu, Member IEEE, Wenping Cao, Senior Member IEEE, Jiande Wu, Bing Ji, Member IEEE, \\ Derrick Holliday
}

\begin{abstract}
This paper proposes a new thermography-based maximum power point tracking (MPPT) scheme to address photovoltaic (PV) partial shading faults. Solar power generation utilizes a large number of PV cells connected in series and in parallel in an array, and which are physically distributed across a large field. When a PV module is faulted or partial shading occurs, the PV system sees a non-uniform distribution of generated electrical power and thermal profile, and the generation of multiple maximum power points (MPPs). If left untreated, this reduces the overall power generation and severe faults may propagate resulting in damage to the system. In this paper, a thermal camera is employed for fault detection and a new MPPT scheme is developed to alter the operating point to match an optimized MPP. Extensive data mining is conducted on the images from the thermal camera in order to locate global MPPs. Based on this, a virtual MPPT is set out to find the global MPP. This can reduce MPPT time and be used to calculate the MPP reference voltage. Finally, the proposed methodology is experimentally implemented and validated by tests on a $600 \mathrm{~W}$ PV array.
\end{abstract}

Index Terms -Fault diagnosis, Maximum power point tracking (MPPT), Partial shading, Photovoltaics, Thermography.

\section{INTRODUCTION}

Photovoltaic (PV) technology is a major means by which to convert solar energy into electricity using semiconductors. Nowadays, grid-connected PV systems are increasingly deployed worldwide to tackle global warming issues [1]-[6].

These systems, however, require a large number of PV modules to be connected in series and in parallel to form a PV array, and then a PV farm which may cover a significant land area. For instance, the world level solar power farm, Sarnia photovoltaic power plant in Canada, spans an area of 950 acres, and produces electricity to power 12,800 homes. A PV array covering such a large area will experience non-uniform insolation, or partial shading [3][4]. In addition, when a PV cell or a module is faulty, it may generate a reduced power or even become a load to consume power. These two phenomena similarly affect the array terminal characteristics and their consequences can be severe. Firstly, the generated electrical

Manuscript received Feb 18, 2014; revised Apr 24, 2014. This work is sponsored by the National Natural Science Foundation of China (51207138). power can drop sharply. Secondly, the non-uniform distribution of generated electricity causes hotspots and multiple maximum power points (MPPs). If left untreated, the fault can propagate to the neighboring components to cause a system failure. Multiple MPPs also result in increased power loss if the system still operates at the original MPP. As a result, it is of prime importance to diagnose any PV faults and subsequently to match the new operating condition.

In the literature, various methods are reported in use to detect PV faults [7]-[11] and to improve MPPT algorithms [12]-[26]. Currently, thermography is proven to be effective in identifying aging cells and hotspots [10][11] and in visualizing PV panel surface temperature [7]. The temperature of PV panels is important in evaluating the PV arrays' safety operation and this cannot be obtained from voltage and current sensors. Furthermore, because of the development of compressed sensing technologies, the cost of thermal camera is reducing dramatically in recent years, allowing a wide application of thermal cameras in PVs. Under uniform insolation conditions, constant voltage control, perturb \& observe $(\mathrm{P} \& \mathrm{O})$ and incremental conduction (IncCond) are the commonly used MPPT techniques [12][13]. They are easy to implement in the controller but have slow response speed, oscillation around the MPP in steady state, and even tracking in wrong way under rapidly changing atmospheric conditions [14]. However, the output characteristics of PV arrays are nonlinear and change with solar radiation and the PV's temperature. Under non-uniform insolation condition, however, traditional MPPT methods cannot distinguish local MPPs from the global MPP [15]. Other control methods such as Fibonacci sequence, chaos search theory, neural-network, particle swarm optimization (PSO) [16]-[18][25], fuzzy logic [19][20], and restricted voltage window search, variable size IncCond, power-increment-aided IncCond and distributed MPPT [5][6][21-24][26] have also been applied in an attempt to solve this problem. Nonetheless, these methods are either overly complicated or computationally costly. There is little work reported to search the MPP by virtual methods (without a need to track changing working points of the array).

This paper proposes a new method to combine a fault diagnosis technology with the MPPT scheme to achieve a system optimization in terms of power generation and fault suppression. This study analyzes thermal images extensively, 


\section{IEEE TRANSACTIONS ON POWER ELECTRONICS}

characterizes the partial shading faults, and uses these data to track a global MPP for an optimized system operation.

\section{PROPOSED MPPT UNDER NON-UNIFORM CONDITIONS}

\section{(a) First MPP tracking and model building}

The electrical characteristics of PVs are influenced by both temperature and illumination. The electrical model of the PV module is expressed by Eq. (1) [2].

$$
I=I_{\mathrm{L}}-I_{\mathrm{o}}\left[\exp \left(\frac{\varepsilon \cdot V}{T_{m}}\right)-1\right]
$$

where $I$ is the PV module output current, $I_{L}$ is the photo current, $I_{o}$ is the saturated current, $V$ is the PV module output voltage, $T_{m}$ is the $\mathrm{PV}$ module temperature, and $\varepsilon$ is the coefficient related to the characteristics of the PV module, which can be calculated using Eq. (2).

$$
I_{m p p_{-} r e f}=I_{s c_{-} r e f}-\frac{I_{s c_{-} r e f}}{\exp \left(\frac{\varepsilon \cdot V_{o c_{-} r e f}}{T_{\text {ref }}}\right)-1}\left[\exp \left(\frac{\varepsilon \cdot V_{\text {mpp_ref }}}{T_{\text {ref }}}\right)-1\right]
$$

where $I_{m p p_{-} \text {ref, }} I_{\text {sc } \_ \text {ref }}$ and $V_{\text {oc } \_ \text {ref }}$ are the MPP current, short current, and open voltage at standard conditions [2].

According to the temperature distribution across the PV array using thermography, a faulty PV array condition can be clearly identified [7] so that the maximum healthy section can be separated from the faulty PV array. In Fig. 1, a section of PV array is subjected to partial shading and is labelled unhealthy. The PV array in row $b$ and column $a$ can be divided into two sub-sections: unhealthy section (I) and healthy section (I). In healthy section (I), all modules in every string are healthy, indicating one MPP in this section (i.e. the first local MPP). The healthy section is composed by a $b \times y$ array, where $y$ is the column number of healthy section (I). The unhealthy section is composed by a $b \times(a-y)$ array. Based on the thermal profile obtained using thermography, the maximum power point in the healthy section is given by Eq. (3):

$$
V_{\text {array_1 }}=y \cdot V_{\text {mp _ref }}\left[1+k_{T}\left(T_{H}-T_{\text {ref }}\right)\right]
$$

where $V_{m p p-r e f}$ is the module's MPP voltage under the reference condition with reference temperature $T_{r e f} ; k_{T}$ is the voltage temperature coefficient. The healthy module temperature $T_{H}$ can be measured using thermography. $V_{\text {array }-1}$ is the first local MPP voltage. The output power from the healthy section can be expressed by Eq. (4):

$$
P_{1}=b \cdot y \cdot P_{m p p}+\Delta P_{1}
$$

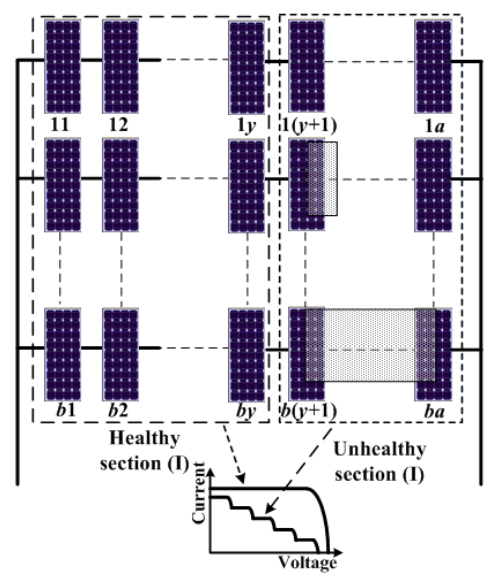

Fig. 1 Separation of healthy section from faulty section.

where $P_{m p p}$ is the maximum power of a healthy module (e.g. module $b 1$ in Fig. 1). $\Delta P_{1}$ is the power error. As shown in Fig. 1 , all the modules in the unhealthy section of row $b$ are faulty; and only $b \times y$ module is capable of generating electricity. This corresponds to a local MPP. In other strings (e.g. row 1 in Fig. 1), $y$ module and other modules can generate electricity. The operating point of the healthy modules lies in the constant current area (i.e. MPP'), as shown in Fig. 2(a). In effect, $V_{m p p}$ is the MPP voltage of the PV module. $\Delta P$ is the output power difference between modules. In the healthy section (I), the total power error that exists between MPP and MPP' is defined by Eq. (5).

$$
\Delta P_{1}=y \cdot(b-z) \cdot \Delta P=y \cdot(b-z)\left(1-k_{m p p_{-} i}\right) \cdot P_{m p p}
$$

where $z$ is the number of strings where all the modules are faulty in the unhealthy section (I); $k_{m p p-i}$ is the short current coefficient (commonly 0.9).
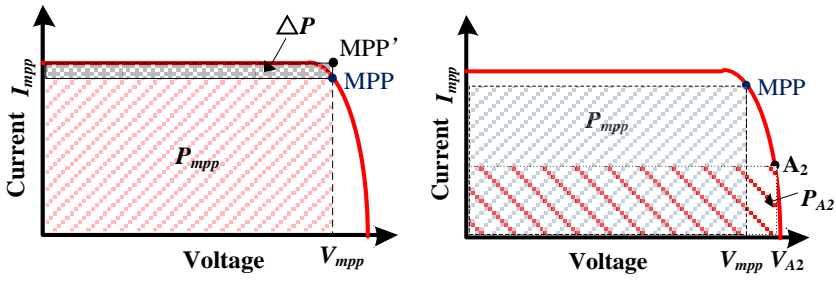

(a) Working point of the healthy section (I). (b) Shift of working point Fig. 2 Operating conditions of the healthy section.

When the PV array operates at $V_{\text {array }-1}$, and the maximum power of the healthy PV module can be calculated using Eq. (6):

$$
P_{m p p}=\frac{I_{\text {array }} \cdot V_{\text {array_1 }}}{b \cdot y+(b-z)\left(1-k_{\text {mpp_i }}\right) \cdot y}
$$

where $P_{m p p}$ is the maximum power of the healthy PV module, and $I_{\text {array }}$ is the array output current.

Given the maximum power, the MPP voltage and the module temperature, the healthy PV module approximate model can be derived as follows,

$$
I_{L}=\frac{P_{m p p}}{k_{m m p_{-} i} \cdot V_{m p p}}
$$




$$
\begin{gathered}
I_{o}=\frac{I_{L}-\frac{P_{m p p}}{V_{m p p}}}{\exp \left(\frac{\varepsilon \cdot V_{m p p}}{T_{H}}\right)-1} \\
I=\frac{P_{m p p}}{k_{m m p_{-} i} \cdot V_{m p p}}-\frac{\frac{P_{m p p}}{k_{m m p} \cdot V_{m p p}}-\frac{P_{m p p}}{V_{m p p}}}{\exp \left(\frac{\varepsilon \cdot V_{m p p}}{T_{H}}\right)-1}\left[\exp \left(\frac{\varepsilon \cdot V}{T_{H}}\right)-1\right]
\end{gathered}
$$

\section{(b) Virtual MPPT}

In the unhealthy section (I), there are multi-local maximum power points caused by the faulty PV modules. The full faulty string is dislodged from the faulty section while the healthy section (II) and the unhealthy section (II) can be separated from the unhealthy section (I), as shown in Fig. 3. The size of the healthy section (II) is defined by rows of $(b-z)$ and columns of $\left(a-y-y_{1}\right)$, whilst the unhealthy (II) is of rows of $(b-z)$ and column of $\left(y_{1}-y\right)$.

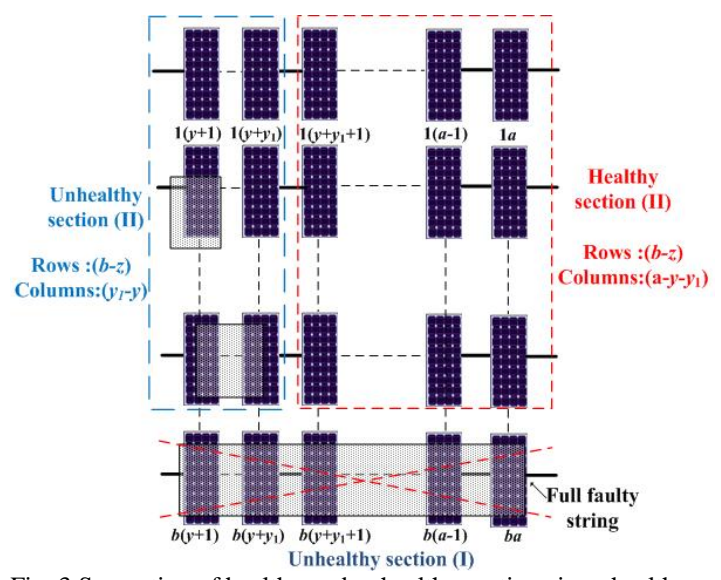

Fig. 3 Separation of healthy and unhealthy sections in unhealthy section (I)

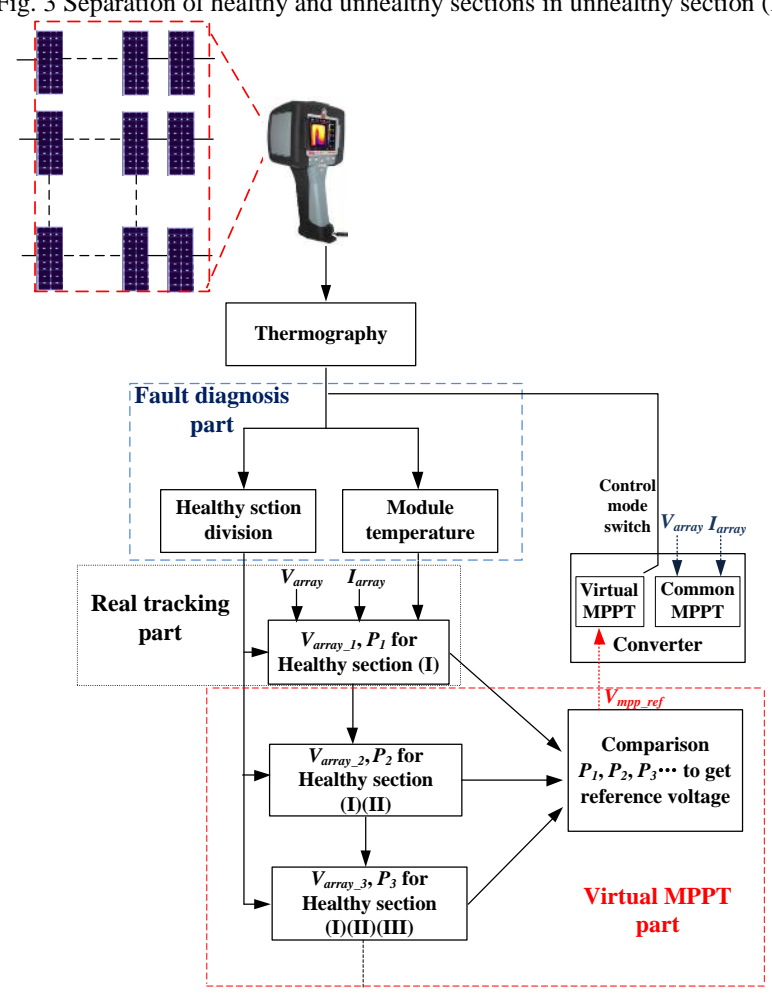

Fig. 4 Flow chart of the proposed MPPT scheme.

To combine the generated power from both the healthy section (I) and healthy section (II), the array MPP voltage is:

$$
\begin{aligned}
V_{\text {array_2 }} & =V_{\text {array_1 }}+\left(a-y_{1}-y\right) \cdot V_{\text {mpp_ref }}\left(1+k_{T}\left(T_{H}-T_{\text {ref }}\right)\right) \\
& =\left(a-y_{1}\right) \cdot V_{\text {mp _ref }}\left(1+k_{T}\left(T_{H}-T_{\text {ref }}\right)\right)
\end{aligned}
$$

where $V_{\text {array-2 }}$ is the voltage of the second local MPP.

However, the working point of the healthy modules in the unhealthy string (row $b$ in Fig. 3) is different to other local MPPs. That is, the working point is shifted to $\mathrm{A}_{2}$, as presented in Fig. 2(b). The voltage for the healthy modules in the row where all modules of the unhealthy section (I) are faulty, is

$$
V_{A 2}=\frac{V_{m p p} \cdot\left(a-y_{1}\right)}{a-y}
$$

If the healthy section (II) takes part in power generation, the operating point of the healthy PV modules of the faulty string in healthy section (I) will be changed, as well as the total power loss. When considering the healthy sections (I) and (II), the total power output and the total power loss can be found:

$$
\begin{gathered}
P_{\text {gain }}=(b-z)\left(a-y-y_{1}\right) P_{m p p}+\Delta P_{2} \\
P_{\text {loss }}=z \cdot y \cdot\left(P_{m p p}-P_{A 2}\right)
\end{gathered}
$$

where $\Delta P_{2}$ is the power error, similar to $\Delta P_{1} P_{A 2}$ is the output power of healthy modules in the row where all modules of the unhealthy section (I) are faulty, (e.g. module $b 1$ in Fig.1). By combining Eq (9) with Eq. (11), $P_{A 2}$ can be calculated. If $P_{\text {gain }}$ is greater than $P_{\text {loss }}$, the output power of array reference voltage $V_{\text {array-2 }}$ is greater than that for $V_{\text {array-1. }}$. The reverse is also true.

Likewise, further healthy sections (say, III) can be separated from the unhealthy section (II), and calculations and comparisons can be carried out until a global MPP is found. In PV array applications, all PV system information (including PV array current, voltage and thermography) are collected and sent to the central control computer via Can Bus. After information process including thermography recognition, fault diagnosis and virtual MPPT, the reference voltage signal is generated and sent to the PV converter via the CAN Bus. This process is illustrated in Fig. 4 in a flow chart. Firstly, the thermographical results are interpreted, the healthy section (I) is divided and the module temperatures are obtained. The PV array is control to work at the reference voltage $V_{\text {array-1 }}$. Based on the measured current and voltage, the PV module model can be established at current condition. From the fault distribution characteristics, the output powers $P_{2}, P_{3}$ can be calculated without PV array working at corresponding points. The output powers $P_{1}, P_{2}$, $P_{3} \ldots$ are thus compared to find a global maximum power point. Once this is achieved, the reference voltage is found and used for the MPPT.

\section{EXPERIMENTAL VERIFICATION}

An experimental platform was constructed. A $2 \times 3 \mathrm{PV}$ array is employed to verify the proposed MPPT scheme. The main module parameters: $V_{o c-\text { ref }}=21.8 \mathrm{~V}, I_{s c \text {-ref }}=6.23 \mathrm{~A}, V_{\text {mpp-ref }}=17 \mathrm{~V}$, $I_{m p p-r e f}=5.69 \mathrm{~A}$, the voltage temperature coefficient $=-0.36 \% / \mathrm{K}$, and the current temperature coefficient $=0.06 \% / \mathrm{K}$. After obtaining thermographical images, data analysis is performed. The thermal camera allows identifying any important defects on 
the PV module and the mean value of the temperature can be used as a good approximation in the proposed procedure since the temperature difference on the same module is insignificant. The following step is segmenting the PV sections and locating the first MPP. Two typical PV faults are adopted for validation purposes, each having a different global MPP.

\section{(a) Single module fault in one string}

Fig. 5(a) shows a single module fault in one string with a thermal image. As presented in Fig. 5(b), the module temperatures in the healthy section are $19.3^{\circ} \mathrm{C}, 19.3^{\circ} \mathrm{C}$ and $19.4^{\circ} \mathrm{C}$, respectively, whilst the PV surface temperatures in the faulted string are $22.5^{\circ} \mathrm{C}, 22.4^{\circ} \mathrm{C}$ and $19.4^{\circ} \mathrm{C}$, respectively. It is clear that No. 23 module is faulted which causes a non-uniform temperature distribution.

By thermographical analysis, the healthy section (I) is a $2 \times$ 2 array and the first MPP is $34.7 \mathrm{~V}$, calculated from Eq. 15. Fig. 5 (c) and (d) present the PV output curves. As illustrated in Fig. 5(d), $V_{\text {array-1 }}$ is $35.1 \mathrm{~V} . P_{m p p-l}$ is $186.5 \mathrm{~W}$ and the MPP power of the healthy module $\left(P_{m p p}\right)$ is $45.5 \mathrm{~W}$.

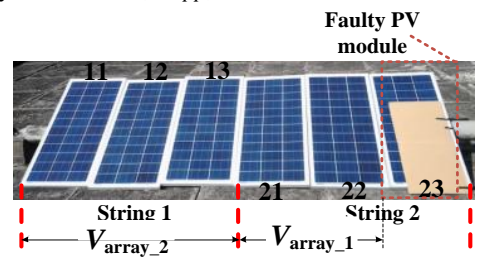

(a) Faulty PV array

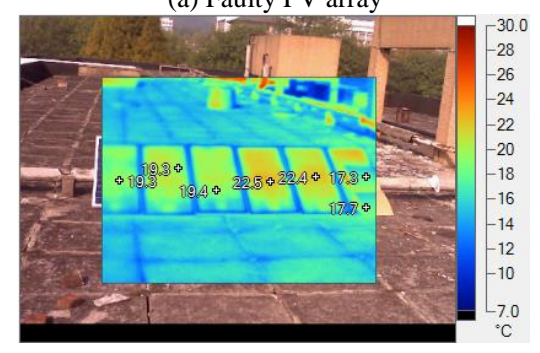

(b) Thermal image

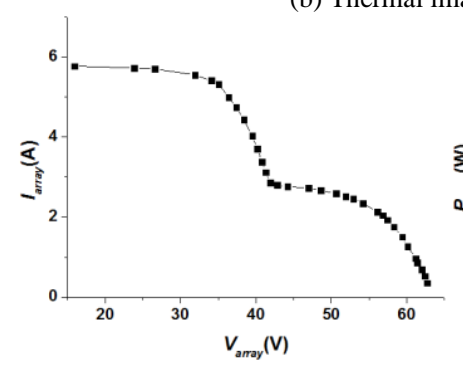

(c) Current-voltage curve

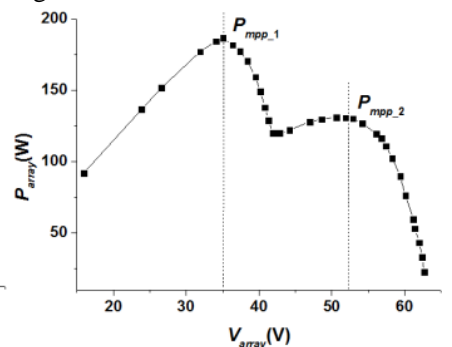

(d) Power-voltage curve
Fig. 5 Experimental tests for a single-module fault in one string.

The healthy section (II) is a $1 \times 1 \mathrm{PV}$ array, the second MPP is $52.6 \mathrm{~V}$, calculated from Eq. 10 . Because the unhealthy module in the faulted string is short-circuited by a bypass diode, the output voltage of the healthy modules (No. 21 and 22) in the same string is $26.3 \mathrm{~V}$. The power gain is $P_{m p p}$ in the healthy section (II). Based on the MPP voltage, the output power and surface temperature, the power loss can be found by following equations:

$$
I_{L}=\frac{P_{m p p}}{k_{m m p_{-} i} \cdot V_{m p p}}=\frac{45.5}{17.5 \times 0.913}=2.85(\mathrm{~A})
$$

$$
\begin{gathered}
I=\frac{P_{m p p}}{k_{m m p_{-} i} \cdot V_{m p p}}-\frac{\frac{P_{m p p}}{k_{m m p_{-} i} \cdot V_{m p p}}-\frac{P_{m p p}}{V_{m p p}}}{\exp \left(\frac{\varepsilon \cdot V_{m p p}}{T_{H}}\right)-1}\left[\exp \left(\frac{\varepsilon \cdot V}{T_{H}}\right)-1\right]=0.373(\mathrm{~A}) \\
P_{\text {loss }}=2 P_{m p p}-2(I \cdot V)=2 \times 45.5-2 \times(0.373 \times 26.3)=71.38(\mathrm{~W})(16)
\end{gathered}
$$

By comparing with the power loss without actual MPP tracking, the output power at $V_{\text {array-1 }}$ is larger than that at $V_{\text {array-2. }}$. As presented in Fig. 5(d), the MPP voltage is $35.1 \mathrm{~V}$. The power output from $V_{\text {array-1 }}$ is greater than that from $V_{\text {array-2, }}$, which is in agreement with the theoretical analysis. After searching the first local MPP $\left(P_{m p p-1}\right)$, the global MPP can be deduced, following the proposed MPPT procedure in Fig. 4.

\section{(b) Two-module faults in one string}

Fig. 6(a) shows the two module faults in one string with their thermal image in Fig. 6(b). Because of a partial shadow, the faulted PV string has a higher temperature than the healthy string. As presented in Fig. 6(b), the module temperatures for healthy panels 11,12 and 13 are $25.3^{\circ} \mathrm{C}, 25.3{ }^{\circ} \mathrm{C}$ and $25.2^{\circ} \mathrm{C}$, respectively. The unhealthy module temperatures in the faulted string are not uniform: $22.2^{\circ} \mathrm{C}$ for faulted module No. $22 ; 27.3$ ${ }^{\circ} \mathrm{C}$ for the faulted module No. 23 ; and $27.5^{\circ} \mathrm{C}$ for the healthy module No. 21. Owing to the working point of the PV array, the healthy module (No. 21) in the faulted string is open circuited and thus its surface temperature is similar to the uncovered part of the faulty modules.

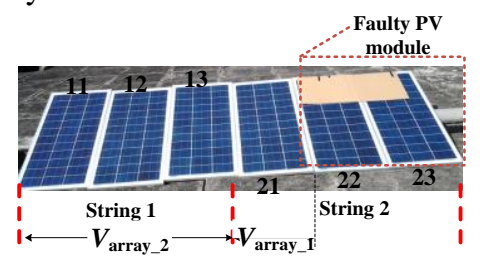

(a) Faulty PV array

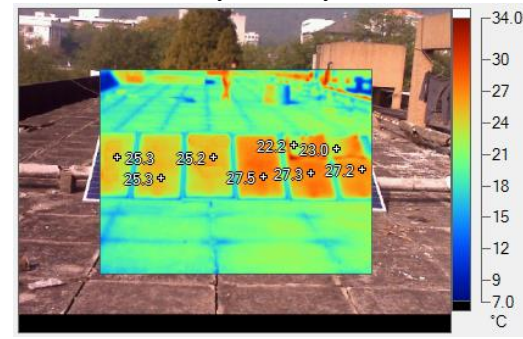

(b) Thermal image

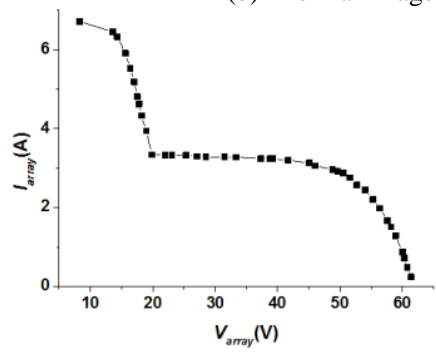

(c) Current-voltage curve

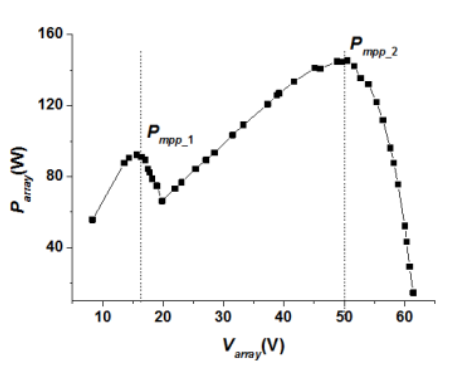

(d) Power-voltage curve
Fig. 6 Experimental tests for the two-module faults in one string.

By thermographical analysis, the healthy section (I) is a $2 \times 1$ array and the first MPP is calculated to be 17V. Fig. 6(c) and (d) are the PV output curves. From Fig. 6(d), $V_{\text {array }-1}$ is $16.5 \mathrm{~V}$ and $P_{m p p-1}$ is $92.5 \mathrm{~W}$ and $P_{m p p}$ is $43 \mathrm{~W}$. Since the PV panel surface temperature read by the thermal camera is used to represent the 
PV cell temperature, there exists a small error in the MPP prediction.

Next, the healthy section (II) is actually a $1 \times 2 \mathrm{PV}$ array and the second MPP is $49.5 \mathrm{~V}$ from calculations. According to Eq. 12 , the power output is $2 P_{m p p}$ in the healthy section (II). Because there are two unhealthy modules in the faulted string, the faulted string cannot work at $V_{\text {array-2}}$, and all the modules are shorted. The power loss is $P_{m p p}$ from Eq. 13. By comparing the power loss with the theoretical gain (without an actual tracking), the output power at $V_{\text {array-2 }}$ is larger than that at $V_{\text {array-1 }}$. As presented in Fig. 6(d), the MPP voltage is $50.2 \mathrm{~V}$ which is close to the theoretical maximum (49.5V); the power at $V_{\text {array-l }}$ is lower than $V_{\text {array-2, }}$ which again is in agreement with the theoretical analysis.

In this $2 \times 3 \mathrm{PV}$ array, two different faults are investigated, which have shown to have different global MPP locations. These results following the proposed virtual MPPT are summarized in Table I. By the proposed method, the thermal images from thermography are first analyzed to identify the fault PV strings and modules; and only the local MPP is tracked to calculate the healthy module MPPs. Based on these, a virtual MPPT procedure is followed to calculate and compare the power gain and the power loss. In essence, there is no need to track the actual operating point in the search for the next local MPP.

TAble I. TeSt Results for the Proposed Virtual MPPT

\begin{tabular}{|c|c|c|c|c|c|c|c|c|c|}
\hline \hline & $\begin{array}{l}\text { Healthy } \\
\text { Section } \\
\text { (I) }\end{array}$ & $\begin{array}{l}\text { Healthy } \\
\text { section } \\
\text { (II) }\end{array}$ & $P_{\text {mpp } 1}$ & $V_{\text {arraj- }}$ & $P_{\text {mpp }}$ & $\begin{array}{c}\text { Power } \\
\text { loss }\end{array}$ & $\begin{array}{c}\text { Power } \\
\text { gain }\end{array}$ & $\begin{array}{c}\text { Global } \\
\text { MPP } \\
\text { voltage }\end{array}$ & $\begin{array}{c}\text { Global } \\
\text { MPP } \\
\text { power }\end{array}$ \\
\hline $\begin{array}{c}\text { Single module } \\
\text { fault in one string }\end{array}$ & $2 \times 2$ & $1 \times 1$ & $186.5 \mathrm{~W}$ & $35.1 \mathrm{~V}$ & $45.5 \mathrm{~W}$ & $71.38 \mathrm{~W}$ & $45.5 \mathrm{~W}$ & $35.1 \mathrm{~V}$ & $186.5 \mathrm{~W}$ \\
\hline $\begin{array}{c}\text { Two-module } \\
\text { faults in one } \\
\text { string }\end{array}$ & $2 \times 1$ & $1 \times 2$ & $92.5 \mathrm{~W}$ & $16.5 \mathrm{~V}$ & $43 \mathrm{~W}$ & $43 \mathrm{~W}$ & $86 \mathrm{~W}$ & $50 \mathrm{~V}$ & $145.1 \mathrm{~W}$ \\
\hline \hline
\end{tabular}

(c) Power converter

In this experiment, a Boost converter is employed to connect the PV array, as shown in Fig. 7(a). The input and the output capacitors are both $470 \mu \mathrm{F}$, and the filter inductor is $0.5 \mathrm{mH}$. The switching device is an IRFP4227PbF MOSFET, the rectifier diode is a FEP30DP device and the switching frequency is set to $50 \mathrm{kHz}$. The experiment results obtained from this converter with the virtual MPPT scheme are presented in Fig. 7(b) and (c). As can be seen that, under a single-module fault, the output voltage is $35.8 \mathrm{~V}$, and the current is $4.98 \mathrm{~A}$. The consequent output power is $178.3 \mathrm{~W}$ with an MPPT error of $4.4 \%$. Under the two-module faults, the output voltage is $50.7 \mathrm{~V}$ and the current is 2.75A. The PV output power is $178.3 \mathrm{~W}$ with an MPPT error of $3.9 \%$.

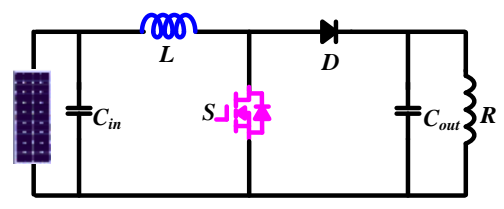

(a) Boost converter

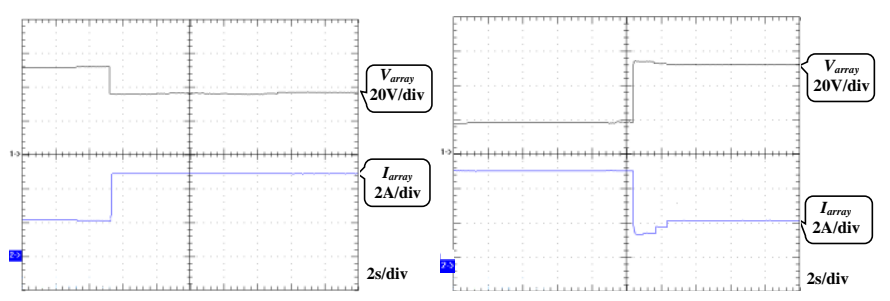

(b) Virtual MPPT under a single -module fault

(c) Virtual MPPT of the two-module fault

Fig. 7 Power converter and experimental results

\section{CONCLUSION}

This paper has combined the use of thermographical fault diagnosis with a new MPPT scheme. The effectiveness of the proposed methodology has been confirmed by experimental tests on six PV panels. The main contributions of this paper are:

(1) Based on thermal data obtained by a thermal camera, the fault PV array can be segregated into healthy and unhealthy sections. Only the MPP in the healthy section (I) is tracked.

(2) Based on the first MPP, the virtual MPPT is employed to identify a global MPP without performing an actual MPPT so that computational time and costs are reduced.

The developed technology can be applied to both grid-connected and standalone PV systems and can also be integrated with existing MPPT schemes.

\section{REFERENCES}

[1] C. R. Sullivan, J. J. Awerbuch, and A. M. Latham, "Decrease in Photovoltaic Power Output from Ripple: Simple General Calculation and the Effect of Partial Shading," IEEE Trans. Power Electron., vol. 28, no. 2, pp. 740-747, 2013.

[2] Y. A. Mahmoud, W. Xiao, H. H. Zeineldin, "A Parameterization Approach for Enhancing PV Model Accuracy," IEEE Trans. Ind. Electron., vol. 60, no.12, pp. 5708-5716, 2013.

[3] S. M. MacAlpine, R. W. Erickson, and M. J. Brandemuehl, "Characterization of Power Optimizer Potential to Increase Energy Capture in Photovoltaic Systems Operating Under Nonuniform Conditions," IEEE Trans. Power Electron., vol. 28, no. 6, pp. 2936-2945, 2013.

[4] L. Gao, R. A. Dougal, S. Liu, and A. P. Iotova, "Parallel-Connected Solar PV System to Address Partial and Rapidly Fluctuating Shadow Conditions," IEEE Trans. Ind. Electron., vol. 56, no. 5, pp. 1548-1556, May 2009.

[5] Y. H. Ji, D. Y. Jung, J. G. Kim, J. H. Kim, T. W. Lee, and C. Y. Won, “A Real Maximum Power Point Tracking Method for Mismatching Compensation in PV Array Under Partially Shaded Conditions," IEEE Trans. Power Electron., vol. 26, no. 4, pp. 1001-1009, Apr. 2011.

[6] F. Wang, X. Wu, F. C. Lee, Z. Wang, P. Kong, F. Zhuo, "Analysis of Unified Output MPPT Control in Subpanel PV Converter System," IEEE Trans. Power Electron., vol. 29, no. 1, pp. 159-169, May 2014.

[7] Y. Hu, B. Gao, X. Song, G. Tian, K. Li, X. He, "Photovoltaic fault detection using a parameter based model," Solar Energy, vol. 96, pp. 96-102, Oct. 2013.

[8] G. Acciani, G. B. Simione and S. Vergura, "Thermographic analysis of photovoltaic panels," International Conference on Renewable Energies and Power Quality (ICREPQ'10), Granada (Spain), 2010.

[9] Z. Zou, Y. Hu, B. Gao, W. L. Woo and X. Zhao, "Study of the Gradual Change Phenomenon in the Infrared Image When Monitoring Photovoltaic Array," Journal of Applied Physics, vol. 115 no. 4, Jan. 2014.

[10] S. Vergura, F. Marino "A Diagnostic Workflow and Software Platform for PV Modules," International Conference on Renewable Energies and Power 
Quality (ICREPQ'14), Cordoba (Spain), 8-10 April 2014.

[11] M. Simon and E. L. Meyer, "Detection and analysis of hot-spot formation in solar cells," Solar Energy Materials and Solar Cells, vol. 94, no. 2, pp. 106-113, 2010.

[12] B. Subudhi, and R. Pradhan, "A Comparative Study on Maximum Power Point Tracking Techniques for Photovoltaic Power Systems," IEEE Trans. Sustainable Energy, vol. 4, no. 1, pp. 89-98, Jan. 2013.

[13] M. A. G. de Brito, L. Galotto, L. P. Sampaio, G. de Azevedo e Melo, C. A. Canesin, "Evaluation of the Main MPPT Techniques for Photovoltaic Applications," IEEE Trans. Ind. Electron., vol. 60, no. 3, pp. 1156-1167, Nov. 2013.

[14] B. Amrouche1, M. Belhamel and A. Guessoum, "Artificial intelligence based P\&O MPPT method for photovoltaic systems," Revue des Energies Renouvelables ICRESD-07 Tlemcen, pp. 11-16, 2007.

[15] G. Carannante, C. Fraddanno, M. Pagano, and L. Piegari, "Experimental Performance of MPPT Algorithm for Photovoltaic Sources Subject to Inhomogeneous Insolation," IEEE Trans. Ind. Electron.,, vol. 56, no. 11, pp. 4374-4380, 2009.

[16] K. Ishaque, and Z. Salam, "A Deterministic Particle Swarm Optimization Maximum Power Point Tracker for Photovoltaic System Under Partial Shading Condition," IEEE Trans. Ind. Electron.,, vol. 60, no. 8, pp. 3195-3206, Aug. 2013.

[17] L. Zhou, Y. Chen, K. Guo and F. Jia, "New approach for mppt control of photovoltaic system with mutative scale dual carrier chaotic search," IEEE Trans. Power Electron., vol. 26, no. 4, pp. 1038-1048, Apr. 2011.

[18] Y. H. Liu, S. C. Huang, J. W. Huang, and W. C. Liang, "A Particle Swarm Optimization-Based Maximum Power Point Tracking Algorithm for PV Systems Operating Under Partially Shaded Conditions," IEEE Trans. Energy Conversion, vol. 27, no. 4, pp. 1027-1035, Dec.2012.

[19]B. N. Alajmi, K. H. Ahmed, S. J. Finney, and B. W. Williams, "A Maximum Power Point Tracking Technique for Partially Shaded Photovoltaic Systems in Microgrids," IEEE Trans. Ind. Electron., vol. 60, no. 4, pp. 1596-1606, Apr. 2013.

[20] N. Tat Luat, and K. S. Low, "A Global Maximum Power Point Tracking Scheme Employing DIRECT Search Algorithm for Photovoltaic Systems," IEEE Trans. Ind. Electron., vol. 57, no. 10, pp. 3456-3467, 2010.

[21] M. Boztepe, F. Guinjoan, G. Velasco-Quesada, S. Silvestre, A.Chouder, E. Karatepe, "Global MPPT Scheme for Photovoltaic String Inverters Based on Restricted Voltage Window Search Algorithm," IEEE Trans. Ind. Electron., vol. 61, no. 7, 3302-3312, Jul. 2014.

[22] Qian Zhang, Changsheng Hu, Lin Chen, Ahmadreza Amirahmadi, Nasser Kutkut, Z. John Shen, and Issa Batarseh, " A Center Point Iteration MPPT Method With Application on the Frequency-Modulated LLC Microinverter," IEEE Trans. Power Electron., vol. 29, no. 3, pp. 1262-1274, Mar. 2013.

[23] Yuncong Jiang, Jaber A. Abu Qahouq, and Tim A. Haskew, "Adaptive Step Size With Adaptive-Perturbation-Frequency Digital MPPT Controller for a Single-Sensor Photovoltaic Solar System," IEEE Trans. Power Electron., vol. 28, no. 7, pp. 3195-3205, Jul. 2013

[24] Hung-Chi Chen and Wen-Jan Lin, "MPPT and Voltage Balancing Control With Sensing Only Inductor Current for Photovoltaic-Fed, Three-Level, Boost-Type Converters," IEEE Trans. Power Electron., vol. 29, no. 1, pp. 29-35, Jan. 2014

[25] Whei-Min Lin, Chih-Ming Hong, and Chiung-Hsing Chen, "Neural-Network-Based MPPT Control of a Stand-Alone Hybrid Power Generation System," IEEE Trans. Power Electron., vol. 26, no. 12, pp. 3571-3581, Dec. 2011.

[26] Guan-Chyun Hsieh, Hung-I Hsieh, Cheng-Yuan Tsai, and Chi-Hao Wang, "Photovoltaic Power-Increment-Aided Incremental-Conductance MPPT With Two-Phased Tracking," IEEE Trans. Power Electron., vol. 28, no. 6, pp. 2895-2911, Jun. 2013

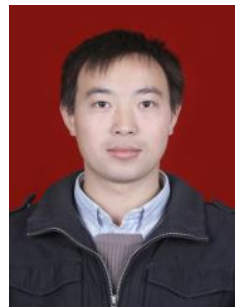

Yihua Hu (M'13) received the B.S. degree in electrical motor drives in 2003, and the Ph.D. degree in power electronics and drives in 2011, both from China University of Mining and Technology, Jiangsu, China. Between 2011 and 2013, he was with the College of Electrical Engineering, Zhejiang University as a Postdoctoral Fellow. Between November 2012 and February 2013, he was an academic visiting scholar with the School of Electrical and Electronic Engineering, Newcastle
University, Newcastle upon Tyne, UK. He is currently a research associate with the Department of Electronic \& Electrical Engineering, University of Strathclyde, Glasgow, UK. He has published more than 20 technical papers in leading journals and conference proceedings. His research interests include PV generation systems, DC-DC/DC-AC converters, and electrical motor drives.

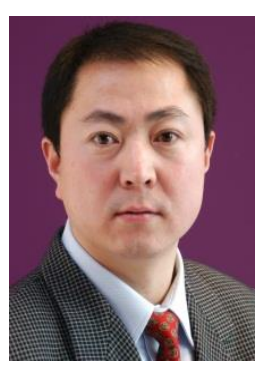

Wenping Cao (M'05-SM'11) received the B.Eng. in electrical engineering from Beijing Jiaotong University, Beijing, China, in 1991; and the Ph.D. degree in electrical machines and drives from the University of Nottingham, Nottingham, U.K., in 2004. He is currently a Senior Lecturer with Queen's University Belfast, Belfast, U.K. His research interests include thermal performance and fault analysis of electric machines, drives and power electronics.

Dr. Cao is the recipient of the Best Paper Award at the LDIA'13 Conference. He serves as an Associate Editor for IEEE TRANSACTIONS ON INDUSTRY APPLICATIONS, IEEE Industry Applications Magazine, IET Power Electronics, and nine other International Journals. He is also a member of the Institution of Engineering and Technology, and a Fellow of Higher Education Academy.

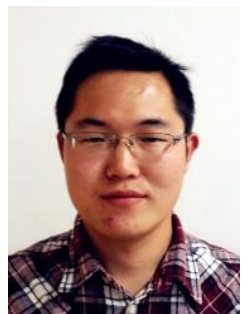

Quanwei Liu received the B.Sc. degree from the College of Electrical and Electronic Engineering, Huazhong University of Science and Technology, Wuhan, China, in 2009. He is currently working toward the Ph.D degree from the College of Electrical Engineering, Zhejiang University, Hangzhou, China. His current research interests include AC micro-grid and its control techniques, energy storage system and voltage source inverters.

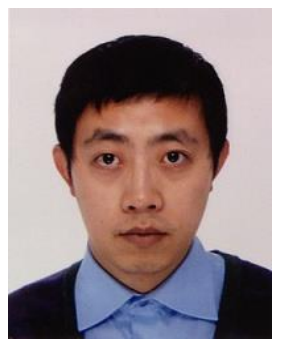

Bing Ji (M'13) received the M.Sc. and Ph.D. degrees in electrical and electronic engineering from Newcastle University, England, in 2007 and 2012, respectively. He was a power electronics engineer with a UK low-emission vehicle company from 2012, where he worked on powertrain development for hybrid electric vehicles and battery management systems. Since 2013, he has been a Postdoctoral Researcher at Newcastle University, where he is involved in accurate power loss measurement and health management for power electronics. His research interests include reliability study of power semiconductor devices, batteries and power electronics converters, function integration of gate drivers, electro-thermal modeling, thermal management and high power-density converter integration for electric vehicle applications. He is also a member of the IET.

Derrick Holliday has research interests in the areas of power electronics, electrical machines and drives. In 1995 he obtained the degree of $\mathrm{PhD}$ from Heriot Watt University and, since then, has held full-time academic posts at the Universities of Bristol and Strathclyde. He has authored or co-authored over 70 academic journal and conference publications. He is currently leading industrially funded research in the field of power electronics for HVDC applications, and is co-investigator on research programmes in the fields of photovoltaic systems and the interface of renewable energy to HVDC systems. 